\title{
SECTION THICKNESS EFFECTS ON MECHANICAL PROPERTIES OF SiMo CGI FOR TURBOCHARGER HOUSINGS
}

\author{
Wilson Luiz Guesser ${ }^{1}$, Ângelo Carlos Gamba ${ }^{1,2}$, Carlos de Souza Cabezas ${ }^{2}$ \\ ${ }^{1}$ UDESC, Joinville-SC $\quad{ }^{2}$ Tupy S.A. Joinville-SC \\ wguesser@tupy.com.br, angelocg@tupy.com.br, cabezas@tupy.com.br
}

\begin{abstract}
In order to decrease fuel consumption and $\mathrm{CO}_{2}$ emissions, the use of downsized engines, with turbochargers, is a very important alternative for engines of passenger cars. Among the materials for exhaust manifolds and for turbocharger housings, silicon molybdenum compacted graphite iron (SiMo CGI) has been used for automotive application, with some advantages over SiMo ductile irons, like thermal conductivity. This paper describes how the section thickness affect the microstructure and mechanical properties of the part. For the experimental work, it was selected two types of test pieces and one turbocharger housing, covering section thickness from 5 to $60 \mathrm{~mm}$, and with solidification times from 17 to 600 seconds. The results show that tensile strength can growth from $450 \mathrm{MPa}$ (the minimum specification value) up to $600 \mathrm{MPa}$ with decreasing section thickness. The results can be used to predict mechanical properties in all places of the casting, with a focus on the critical ones, looking to reduce weight and increase safety of the part.
\end{abstract}

\section{INTRODUCTION}

The requirements for reducing fuel consumption in engines has brought new challenges for the designers and manufacturers of internal combustion engines. The results obtained are based on a large number of innovations in the vehicle. The downsizing approach, aiming to reduce the engine size, brings weight reductions for a large set of components, resulting in a compact and lightweight engine. This technology is normally associated with turbocharging, to change the combustion conditions and to increase the power.

Different ferrous alloys may be used for turbocharger housings, and their selection depends mainly on the temperature of the combustion gases. The same applies to exhaust manifolds [1]. One alloy of increasing use in these applications is compacted graphite iron alloyed with silicon and molybdenum (SiMo CGI), which combines good mechanical properties with oxidation resistance and thermal conductivity.

An important aspect in these components is the geometric complexity, with thin walls (3-4 $\mathrm{mm}$ ) and places of mass concentration, resulting in very distinct properties throughout the piece. Usually, designers consider the physical and mechanical properties as homogenous throughout the casting, using only one value on their component durability simulations. This can lead the designer to avoid reducing wall thickness due to safety issues, when in fact, this 
could be done without concern, as long as the properties on different section thickness are known.

So, for the design of the part, it is necessary to know the relations between casting dimensions and microstructure, and mechanical properties, and that such relationships are used in the design, in order to optimize each part location. In the present work, the variations of microstructure and mechanical properties were studied in different sections, both in specimens and pieces. The work presented here is part of the Master Thesis at UDESC of one of the authors [2].

\section{EXPERIMENTAL PROCEDURES}

It was selected a turbocharger housing, used in an $\mathrm{I} 42.8 \mathrm{~L}$ diesel engine, with section thickness ranging from 4.5 to $50 \mathrm{~mm}$ (figure 1). The solidification simulation, done with Magma, shows that the solidification time (from Liquidus to Solidus temperatures) varies from 38 to 443 seconds, and the solidification rate at the eutectic from 3.65 to $1.02{ }^{\circ} \mathrm{C} / \mathrm{s}$. It was also selected a sample with various diameters (figure 2-a), from 5 to $50 \mathrm{~mm}$, with solidification time and solidification speed at eutectic ranging from 17 to 645 seconds and 21.7 to $0.8^{\circ} \mathrm{C} / \mathrm{s}$, respectively. Another test sample was the ladder sample (figure 2-b), with sections from 8.5 to $60.5 \mathrm{~mm}$, and with solidification time and solidification speed at eutectic ranging from 78 to 396 seconds and 2.9 to $1.06^{\circ} \mathrm{C} / \mathrm{s}$, respectively. For the sample with different diameters, the representative section, used for correlations, was half the diameter, in order to have the same solidification modulus as plates or sections of the casting.

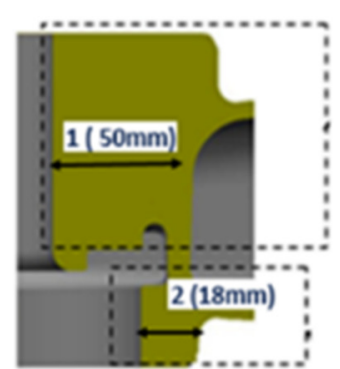

a

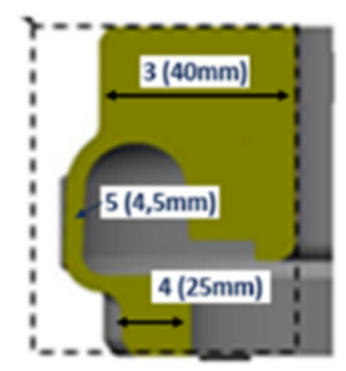

b
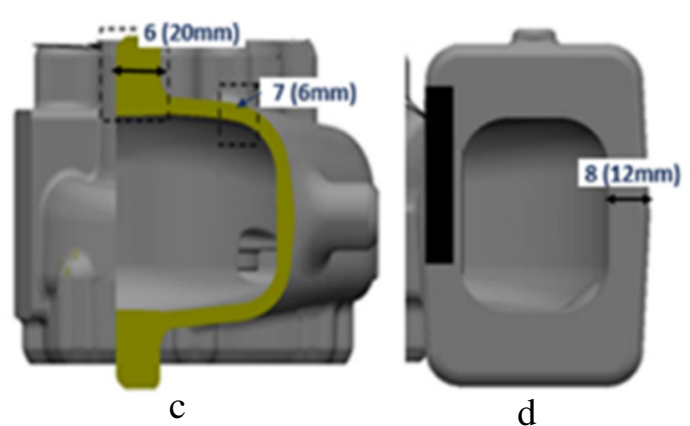

Figure 1. Sections of the turbo housing selected for the experimental work. Application in an I4 diesel engine, 2.8 L, $115 \mathrm{~kW}, 430$ N.m

The melt was produced in an industrial induction furnace, with additions of $\mathrm{Mg}$ and inoculant wires in a $900 \mathrm{~kg}$ ladle, controlling the $\mathrm{Mg}$ addition by an oxygen sensor. Important elements are $\mathrm{C}(3.3 \%)$, Si $(4.3 \%)$ and $\mathrm{Mo}(0.7 \%)$, with the other elements in residual contents. The melt was poured in chemical bonded sand moulds, with the shakeout of the parts after 24 h.

Metallographic and mechanical tests were conducted in all samples. For the turbo housing, the mechanical tests were obtained from a $12 \mathrm{~mm}$ section, indicated in figure $1-\mathrm{d}$. The evaluation of graphite nodularity in the microstructure was done according to a procedure described at [3]. 


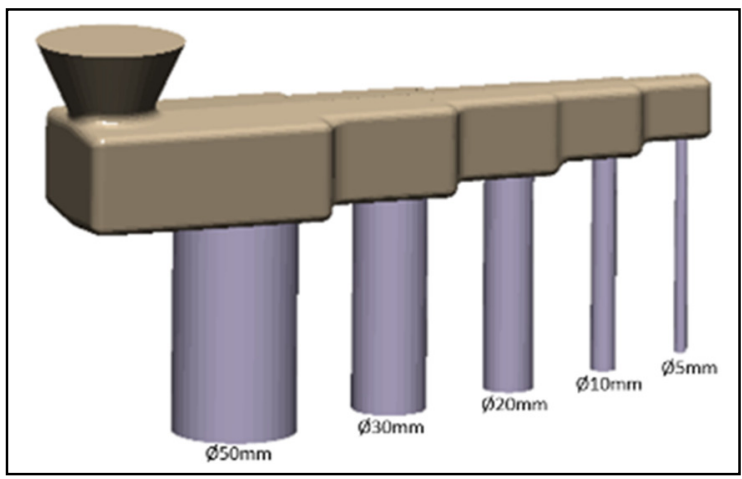

Figure 2. Test pieces with different diameters (a) and sections (b).

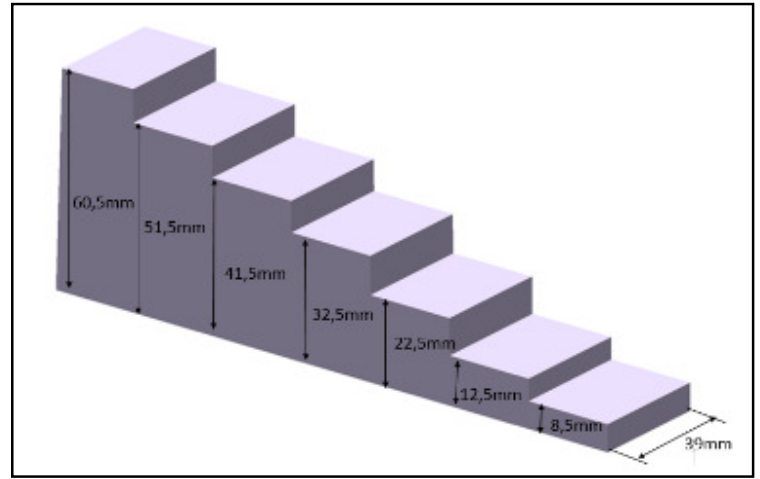

\section{RESULTS AND DISCUSSION}

The microstructure of all samples and parts show graphite particles in worm-shape and some nodules, with a matrix of $80-90 \%$ ferrite and intercellular carbides, associated with pseudo-pearlite (figure 3). The main difference between the samples is the amount of nodules, with a trend of increasing nodularity with decreasing section size.

The section thickness of all specimens was related to some thermal analysis parameters, like solidification time and solidification rate at eutectic, and the results are shown on figures 4 and 5. It can be seen that solidification time and solidification rate at eutectic are related to the section thickness of the part. The relation, expressed by the correlation coefficient $\left(\mathrm{R}^{2}\right)$, is a little better with the solidification time, which express all the solidification phenomena; the solidification rate is more connected to the eutectic reaction.

From the microstructure features, nodularity is the most important one. In the present test samples, nodularity was changed from 12 to $56 \%$. In figure 6 , nodularity was related to section thickness and to solidification time. No valid correlation was found with nodularity and solidification rate at eutectic $\left(\mathrm{R}^{2}=0.24\right)$. Nodularity is high with low section thickness and short solidification time.

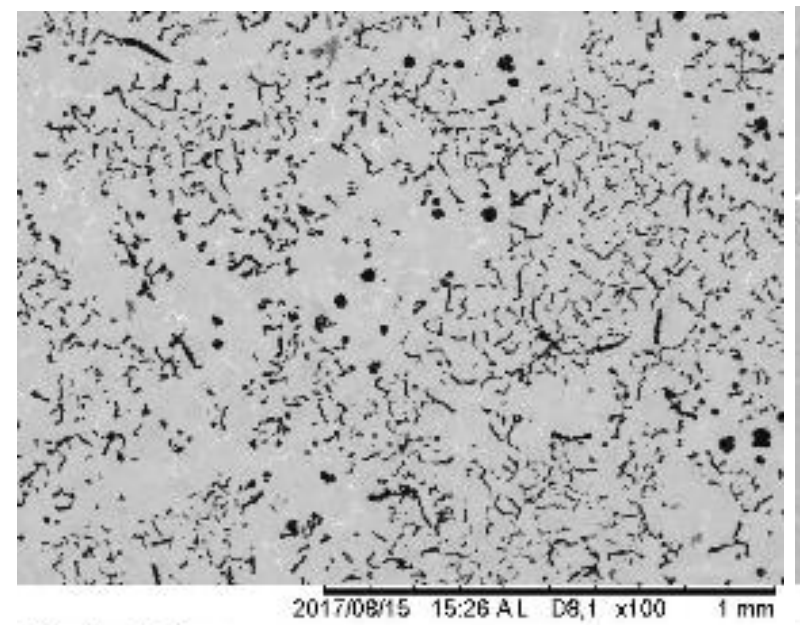

SiMn_Vomi_E0 mm

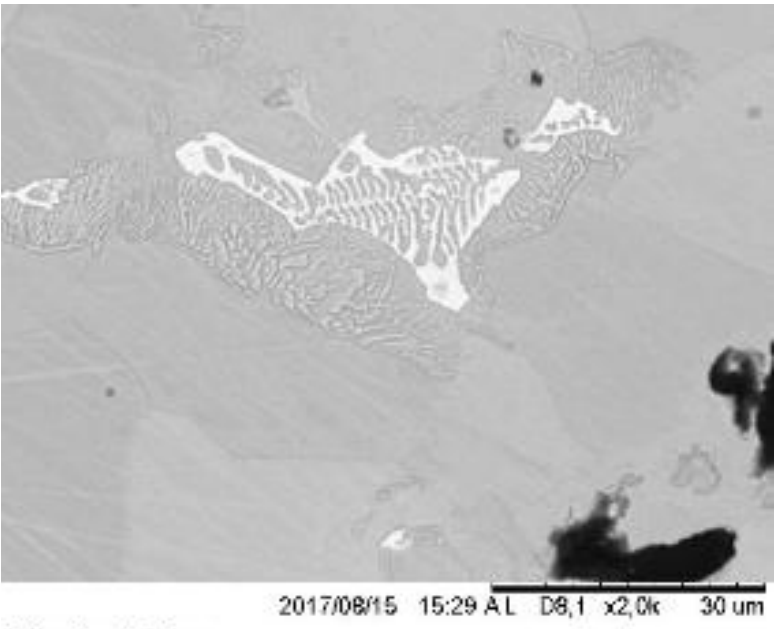
SiMo_Vomi_E0 mm

Figure 3. Microstructure of a SiMo CGI turbine housing. Graphite structure in a $90 \%$ ferrite matrix (a) and intercellular carbides rich in Mo, associated with some "pearlite" (b). 


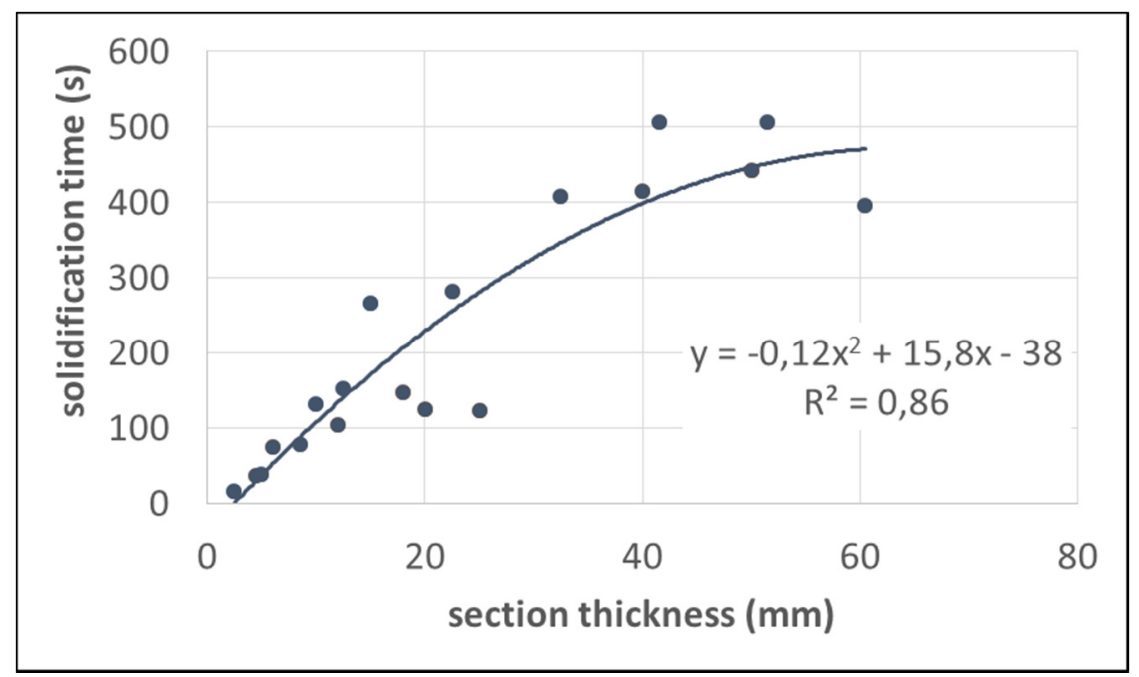

Figure 4. Effect of section thickness on the solidification time, with results of a turbo housing and two types of test samples.

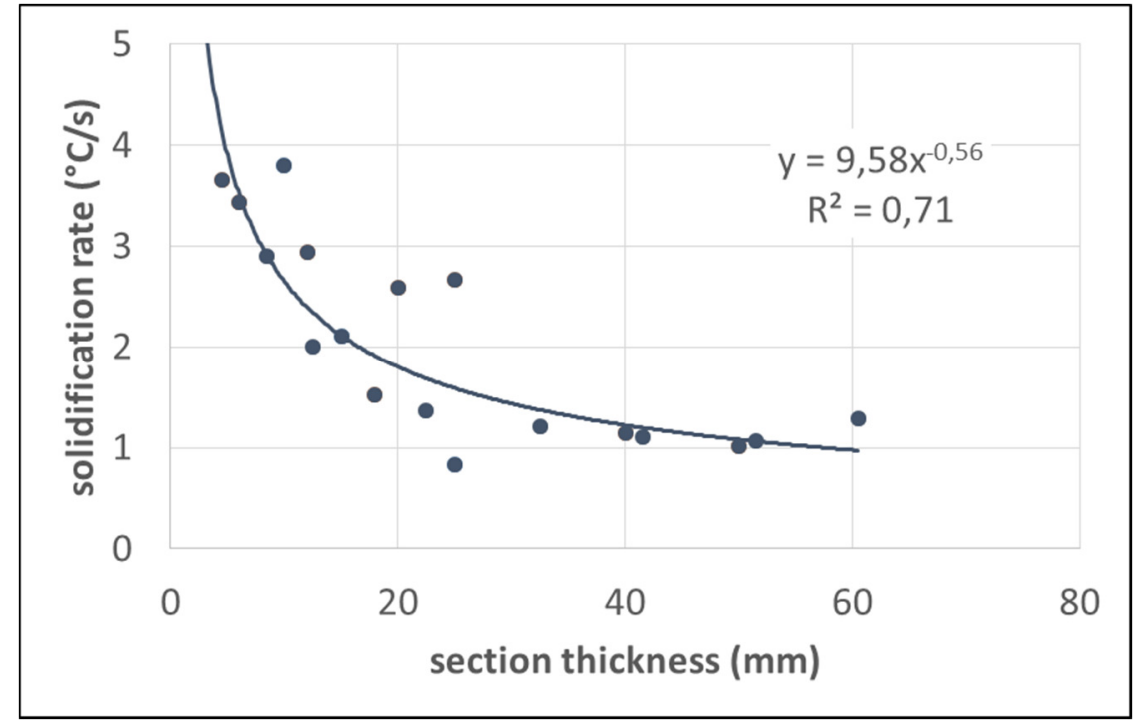

Figure 5. Effect of section thickness on the solidification rate at eutectic, with results of a turbo housing and two types of test samples. 

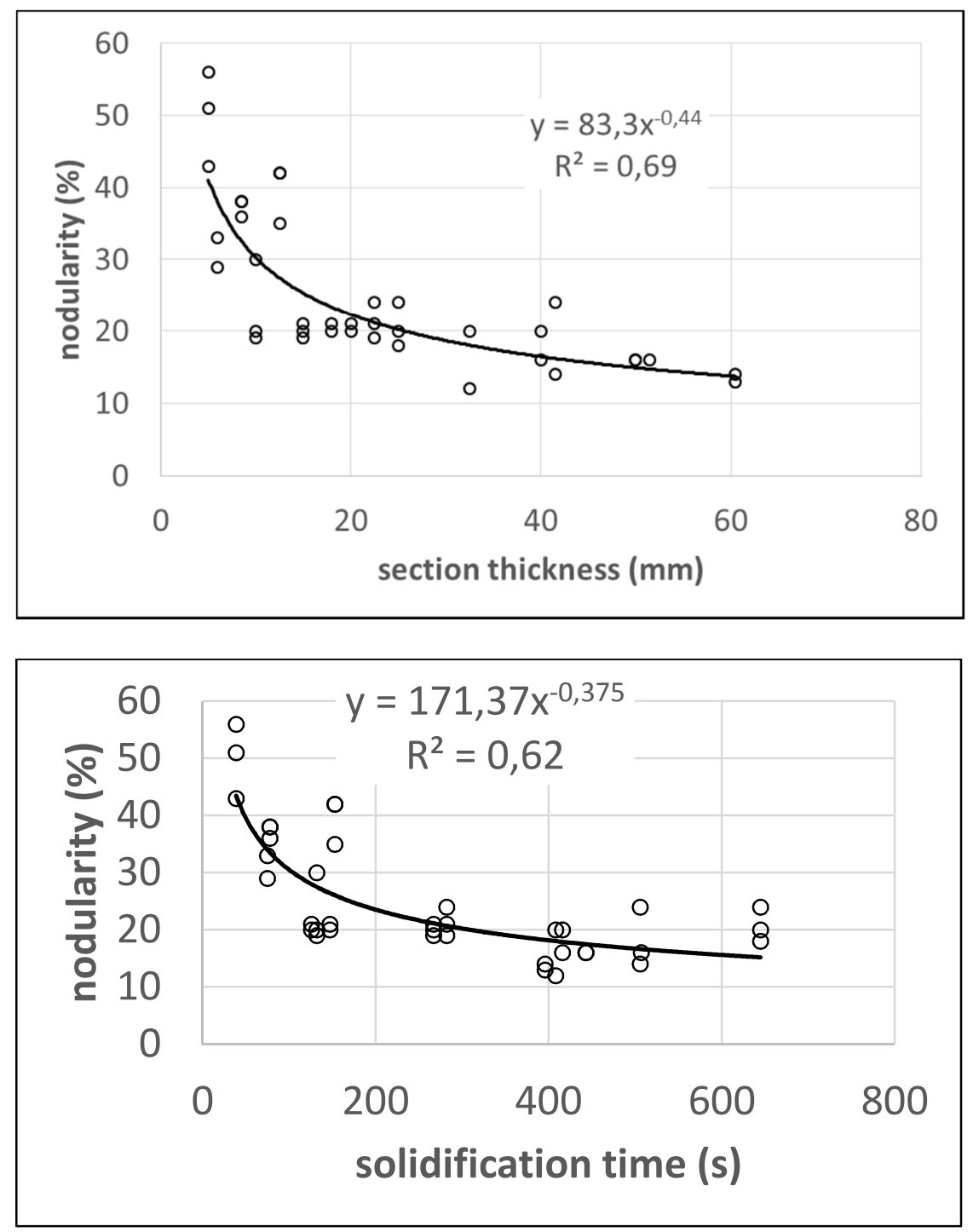

Figure 6. The amount of nodules in compacted graphite microstructure increases with decreasing section thickness (a), associated with lower solidification time (b).

The results of mechanical properties are shown in figures 7 to 9 , in relation with solidification time, solidification rate at eutectic, nodularity and section thickness. The relations obtained for UTS and YS show correlation coefficients $\left(\mathrm{R}^{2}\right)$ between 0.68 to 0.85 , with the best correlation of UTS and YS with the eutectic solidification rate $(0.74$ and 0.81$)$ and with section thickness (0.76 and 0.82).

Comparing the results of figure 9 to those of Scheib et all [4], with a pearlitic CGI, without Mo and with regular Si (2\%), the main differences are related to the Yield Strength, higher in the numbers obtained in the present work of SiMo CGI, probably due to the higher silicon and Mo contents. Comparing the results to those of Ghasemi et all [5], with 4,1\% Si and no Mo, the main differences lies on lower section thickness, with higher strength with the results from the present paper, probably due to the presence of Mo.

The direct estimation of mechanical properties from the section thickness, using figure 9, seems to be the best option, without the need to run a solidification simulation software, and 
with a good agreement with experimental data. This figure 9 (and equations) is the final result of this study and it is recommended to be used in the design of exhaust manifolds and turbo housings, taken the section thickness of different places of the part to estimate the local mechanical properties (UTS and YS). It is recommended to avoid taking places of end of filling, like thin ribs, with very high solidification rates.
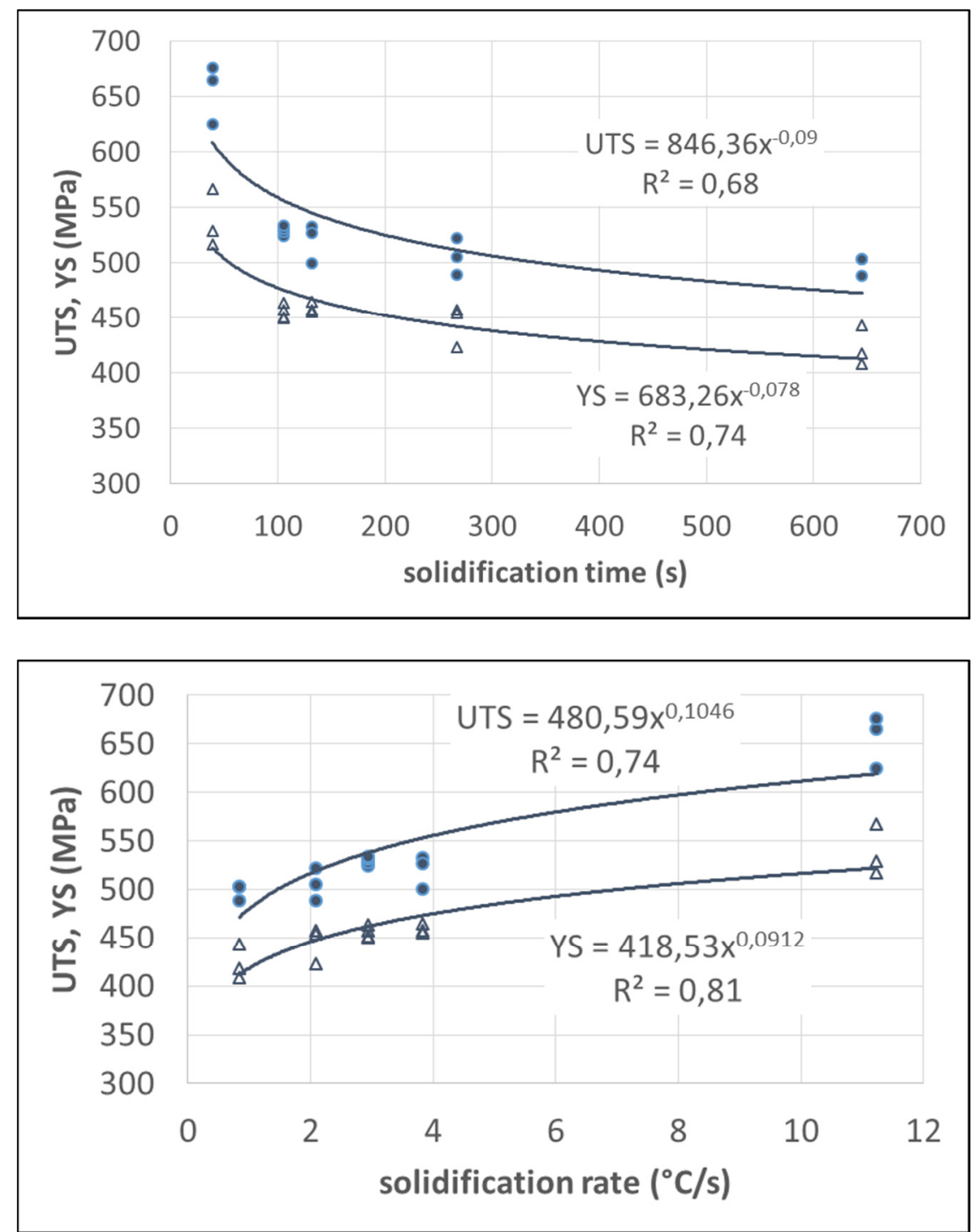

Figure 7. The strength of SiMo CGI increases with decreasing solidification time (a) and with increasing of the eutectic solidification rate (b), because of variation in section thickness. 


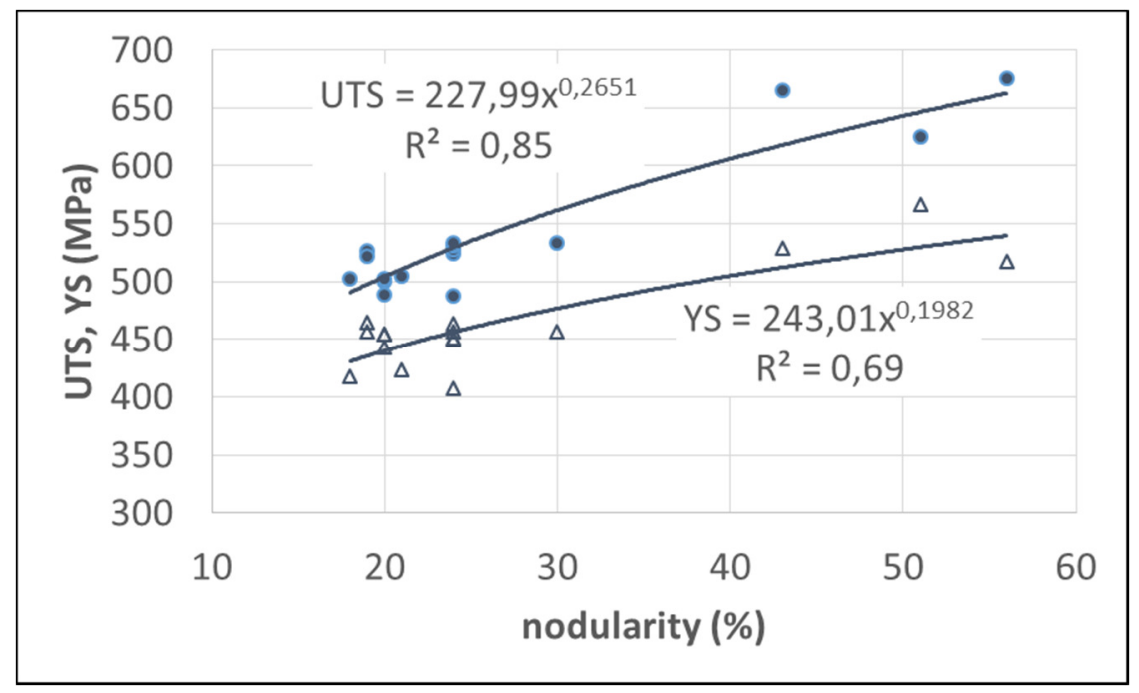

Figure 8. Correlation between nodularity of CGI and the strength (UTS, YS), because of variation of section thickness.

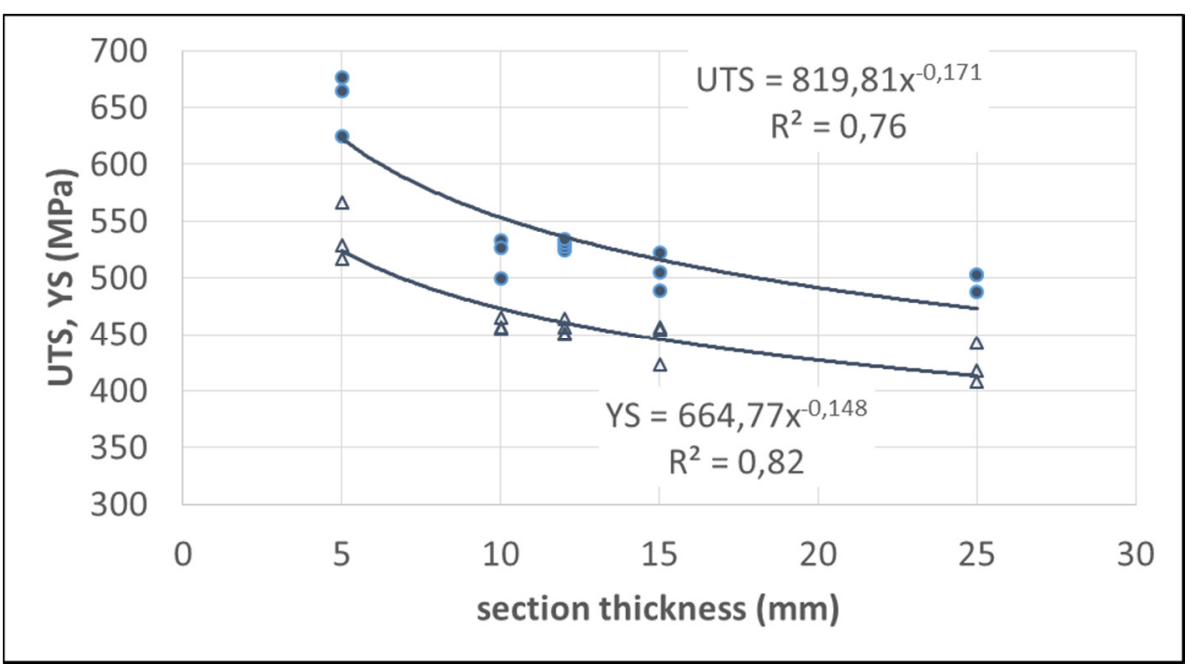

Figure 9. Influence of section thickness on mechanical properties of SiMo CGI.

\section{CONCLUSIONS}

It was found that in SiMo CGI the section thickness affects the microstructure and the mechanical properties. Nodularity and the strength (UTS, YS) of the material increases with decreasing section thickness. With the equations obtained in the present work, it is possible to predict the mechanical properties in all places of a new part, looking for the critical ones, in order to reduce weight and increase safety of the part. 


\section{REFERENCES}

[1] MELLERAS, E; BERNARDINI, P; GUESSER, W. L. Coletores de escape em nodular SiMo. Congresso SAE Brasil, São Paulo, 2003.

[2] GAMBA, A. C. Influência das espessuras das seções nas microestruturas e nas propriedades mecânicas dos ferros fundidos vermiculares SiMo. UDESC, Master Thesis, Joinville, 2017.

[3] DAWSON, S; GUESSER, W.L. Microstructure and characterization of compacted graphite iron. ASM Handbook, vol 1A - Cast Iron Science and Technology, p. 676-685, 2017.

[4] SCHEIB, H; WEISSKOPF, K L; BÄHER, R. Eigenschaften dünnwandiger Gussteile aus GJV - Untersuchungen am Stufenkeil. Giesserei, vol 94, nº 6, p. 180-189, 2007.

[5] GHASEMI, R; OLOFSSON, J; JARFORS, A; SVENSSON, I. Modelling and simulation of local mechanical properties of high silicon solution-strengthened ferritic compacted graphite iron. International Journal of Cast Metals Research, vol 30, n³, p. 125-132, 2017.

\section{ACKNOWLEDGMENTS}

This paper is part of the master thesis of A. Gamba at UDESC, Joinville, Brazil, conducted in the partnership with Tupy and UDESC. 